\title{
Consumo, digestibilidade aparente de nutrientes e balanços de nitrogênio e hídrico de ovinos alimentados com silagens de cultivares de capim-búfel
}

\author{
[Intake, apparent digestibility of nutrients and nitrogen and water balances of sheep fed with \\ buffel grass cultivars silages] \\ R.A. Souza ${ }^{1}$, T.V. Voltolini ${ }^{1}$, G.G.L. Araújo ${ }^{1}$, L.G.R. Pereira ${ }^{2}$, S.A. Moraes ${ }^{1}$, C. Mistura ${ }^{3}$, \\ K.V.J. Belem ${ }^{4}$, G.M.B. Moreno ${ }^{5}$ \\ ${ }^{1}$ Embrapa Semiárido - Petrolina, PE \\ ${ }^{2}$ Embrapa Gado de Leite - Juiz de Fora, MG \\ ${ }^{3}$ Universidade do Estado da Bahia - UNEB - Juazeiro, BA \\ ${ }^{4}$ Aluno de pós-graduação - Universidade Federal do Vale do São Francisco - Petrolina, PE \\ ${ }^{5}$ Aluna de pós-graduação - Universidade Estadual Paulista - UNESP - Jaboticabal, SP
}

\begin{abstract}
RESUMO
Objetivou-se no presente estudo determinar o consumo, digestibilidade aparente da matéria seca e nutrientes, além dos balanços de nitrogênio (BN) e hídrico (BH), de ovinos alimentados com silagens de capim-búfel. As silagens das cultivares de capim-búfel avaliadas foram Tanzânia, Buchuma e Biloela. Utilizaram-se 21 ovinos, machos, castrados, mestiços Santa Inês x Sem Padrão de Raça Definido, com peso corporal médio inicial de $31,8 \pm 3,16 \mathrm{~kg}$, mantidos em gaiolas metabólicas. Foi utilizado um delineamento inteiramente casualizado com sete repetições. Não foram observadas diferenças nos consumos de MS em g/dia $(919,2)$ e porcentagem do peso corporal $(2,9)$. De modo geral, os coeficientes de digestibilidade da matéria seca variaram de $37,7 \%$ a $60,0 \%$. Os BN e BH foram positivos, sendo observados maiores valores de BN para os ovinos alimentados com silagens de capim-búfel dos cultivares Tanzânia (5,1g/dia) e Biloela (3,9g/dia), e maiores BH para os animais alimentados com silagens de capim-búfel dos cultivares Buchuma (1,38kg/animal/dia) e Biloela (1,42kg/animal $/ \mathrm{dia})$. Os cultivares de capim-búfel Tanzânia, Buchuma e Biloela apresentaram bom valor nutritivo, sendo que o capim-búfel na forma de silagem promoveu $60 \%$ do consumo total de água diário do animal.
\end{abstract}

Palavras-chave: Cenchrus ciliaris, conservação de forragem, valor nutritivo

\begin{abstract}
The objective of this present experiment was to determine intake and apparent digestibility of dry matter and nutrients, nitrogen (NB) and water balances (WB) of sheep fed with buffel grass silages. The buffel grass cultivars used were Tanzania, Buchuma and Biloela. 21 male, castrated, crossbred Santa Ines $x$ Non defined genotype sheep, with initial body weight of $31.8 \pm 3.16 \mathrm{~kg}$ were used, kept in metabolic cages. The experimental design was completely randomized with seven replicates. No differences were observed in dry matter intake in g/day (919.2) and \% of body weight (2.9). In general, digestibility coefficients of dry matter varied from $37.7 \%$ to $60.0 \%$. The NB and WB were positive, with higher NB values in sheep fed with Tanzania (5.1g/day) and Biloela (3.9g/day) and higher WB in animals fed with Buchuma (1.38kg/animal/day) and Biloela (1.42kg/animal/day). All cultivars of buffel grass evaluated (Tanzania, Buchuma and Biloela) presented adequate chemical composition, where the silage of buffel grass used corresponded to $60 \%$ of the total daily water intake by sheep.
\end{abstract}

Keywords: Cenchrus ciliaris, conservation of forage, nutritive value

Recebido em 14 de junho de 2011

Aceito em 11 de abril de 2012

E-mail: rafael.araujo@zootecnista.com.br 


\section{INTRODUÇÃO}

O rebanho de caprinos e ovinos da região semiárida do Nordeste gira em torno de 18 milhões de cabeças (Araújo et al., 2010), e tem na pecuária desses ruminantes fonte de proteína animal para a alimentação humana, além de geração de renda, principalmente em decorrência das limitações climáticas que dificultam o cultivo das lavouras.

A disponibilidade de forragem é irregular em função dos períodos de chuva e seca característicos da região semiárida. Além disso, os pastos nativos são insuficientes para atender à demanda de alimento dos animais no período seco do ano.

A fim de tornar suficiente o suporte forrageiro para o período crítico do ano, a conservação de espécies forrageiras, nativas ou exóticas adaptadas, pode ser uma alternativa viável. O capim-búfel por sua vez é uma gramínea exótica bem adaptada às condições de semiárido que apresenta boa produção de forragem e perenização, considerando as características do ambiente (Giulieti et al., 2004).

O capim-búfel é bastante utilizado em pastejo direto, tanto na época das chuvas como no período seco, na forma de "feno em pé", além de ser conservado principalmente na forma de feno no período das águas (Oliveira, 1993). No entanto, a produção de silagem é uma alternativa de conservação de volumosos com o propósito de aumentar a oferta de matéria seca aos rebanhos nos períodos críticos do ano, contribuindo ainda como fonte de água, elemento fundamental para o metabolismo animal.

Todavia, o consumo representa a maior parte das variações na qualidade de um alimento, pois dele vai depender a quantidade total de nutrientes que o animal recebe para a sua mantença, crescimento, reprodução e produção. Da mesma forma, a quantidade de nutrientes absorvidos vai depender da interação entre o consumo e a digestibilidade (Berchielli et al. 2006). Logo, as estimativas do consumo de alimentos por ovinos são importantes para predição do ganho de peso e o estabelecimento das exigências nutricionais dos animais, necessários à formulação das dietas (National..., 2007).
Diante disso, o objetivo do presente estudo foi determinar o consumo, digestibilidade aparente dos nutrientes, balanço de nitrogênio (BN) e hídrico em ovinos alimentados com silagens de três cultivares de capim-búfel.

\section{MATERIAL E MÉTODOS}

O ensaio foi desenvolvido no Campo Experimental da Caatinga, setor de Metabolismo Animal, pertencente à Embrapa Semiárido, localizada em Petrolina/PE. O período experimental foi de 14 dias, sendo que 10 foram destinados à adaptação dos animais e quatro para a coleta de dados

Foram utilizados 21 ovinos, machos, castrados, mestiços Santa Inês x Sem Padrão Racial Definido (SPRD), com $31,8 \pm 3,16 \mathrm{Kg}$ de peso corporal médio inicial.

Foram avaliadas silagens de três cultivares de capim-búfel (Tanzânia, Buchuma e Biloela). Essas silagens foram produzidas a partir de um corte realizado com roçadeira mecânica tracionada por trator, aos 70 dias após o início das primeiras chuvas. Antes do período chuvoso, foi realizado um corte, a aproximadamente $5 \mathrm{~cm}$ de altura do nível do solo. Depois de cortada, a forragem foi picada em forrageira estacionária, obtendo-se partículas cujos tamanhos variaram de 2 a $10 \mathrm{~cm}$.

As silagens foram confeccionadas em silos de tambores plásticos com capacidade para $200 \mathrm{~L}$. O material forrageiro foi compactado nos silos, usando-se êmbolos de madeira e, posteriormente, os silos foram vedados com tampas e braçadeiras plásticas e acondicionados em galpão coberto. Uma amostra do material forrageiro picado, antes da ensilagem, foi encaminhada ao Laboratório de Nutrição Animal (LANA) da Embrapa Semiárido para a realização das análises bromatológicas.

Os animais foram mantidos individualmente em gaiolas metabólicas, providas de comedouros, bebedouros e saleiros, distribuídas em um galpão coberto, ventilado, com piso cimentado. Antes do início da pesquisa, os animais foram pesados e receberam anti-helmínticos.

As silagens foram fornecidas diariamente, às 9:00h e 15:00h. Para as amostras de silagem de 
capim-búfel com teores de PB inferiores a 7\% da MS, foi adicionada ureia a fim de se atingir teores mínimos de 7\% de PB na MS. A quantidade de silagem ofertada diariamente foi calculada em função do consumo apresentado no dia anterior, considerando sobras de aproximadamente $10 \%$.

Antes de distribuir a silagem nos comedouros, durante o período de coleta, foram retiradas amostras das silagens ofertadas e, no dia seguinte, todas as sobras foram coletadas, acondicionadas em sacos de papel e pesadas individualmente, sendo em seguida encaminhadas ao LANA da Embrapa Semiárido para a realização das análises bromatológicas.

As amostras das silagens ofertadas, das sobras e fezes foram pré-secadas em estufa de ventilação forçada a $55^{\circ} \mathrm{C}$, moídas em moinho tipo "Willey" em peneira de $1 \mathrm{~mm}$, sendo compostas as amostras de sobras e fezes de cada animal. Nas amostras de silagens e sobras foram determinados os teores de MS, material mineral $(\mathrm{MM})$, matéria orgânica (MO), proteína bruta
(PB), extrato etéreo (EE), fibra em detergente neutro (FDN), fibra em detergente neutro corrigida para fibra e proteína (FDNcp), fibra em detergente ácido (FDA), fibra em detergente ácido corrigida para fibra e proteína (FDAcp) e lignina, de acordo com as metodologias descritas por Silva e Queiroz (2002).

A hemicelulose (HEM) e a celulose (CEL) foram calculadas por meio de equações: $\mathrm{HEM}=\mathrm{FDN}-$ FDA e CEL = FDA - lignina (Tab. 1). Nas fezes foram determinados os teores MS e PB (Silva e Queiroz, 2002). Para a determinação do consumo e digestibilidade aparente da MS e nutrientes, além da ingestão, excreção de água e balanço hídrico do animal, as análises bromatológicas foram realizadas de forma semelhante a essas descritas anteriormente.

Os carboidratos totais (CHOT) e os carboidratos não fibrosos (CNF) foram obtidos segundo Sniffen et al. (1992), por meio da equações: $\mathrm{CHOT}=100-(\% \mathrm{~PB}+\% \mathrm{EE}+\% \mathrm{MM}), \mathrm{e} \mathrm{CNF}=$ $100-(\% \mathrm{~PB}+\% \mathrm{EE}+\% \mathrm{FDNcp}+\mathrm{MM})$.

Tabela 1. Composição bromatológica das silagens de cultivares de capim-búfel, ofertadas no ensaio de consumo e digestibilidade aparente de nutrientes

\begin{tabular}{|c|c|c|c|}
\hline \multirow{2}{*}{ Variável, \% da matéria seca } & \multicolumn{3}{|c|}{ Cultivares de capim-búfel } \\
\hline & Tanzânia & Buchuma & Biloela \\
\hline Matéria seca, \% do alimento & 44,09 & 42,93 & 35,25 \\
\hline Matéria mineral & 8,36 & 9,05 & 10,90 \\
\hline Fibra em detergente neutro & 77,07 & 77,38 & 73,41 \\
\hline FDNcp & 70,33 & 67,24 & 63,35 \\
\hline Nitrogênio indigestível em detergente neutro & 0,31 & 0,24 & 0,38 \\
\hline Fibra em detergente ácido & 47,25 & 51,85 & 50,49 \\
\hline FDAcp & 43,04 & 46,62 & 43,83 \\
\hline Nitrogênio indigestível em detergente ácido & 0,16 & 0,15 & 0,21 \\
\hline Hemicelulose & 29,81 & 25,53 & 22,93 \\
\hline Celulose & 34,48 & 35,67 & 32,72 \\
\hline Lignina & 11,73 & 11,16 & 12,84 \\
\hline Proteína bruta & 5,90 & 4,69 & 6,56 \\
\hline Proteína bruta* & 8,74 & 5,91 & 8,65 \\
\hline Extrato etéreo & 1,45 & 2,01 & 1,67 \\
\hline Carboidratos totais & 81,44 & 83,03 & 78,78 \\
\hline Carboidratos não fibrosos & 11,11 & 15,79 & 15,43 \\
\hline
\end{tabular}

*corrigido com ureia para 7\% de proteína bruta; FDNcp = fibra em detergente neutro corrigida para cinzas e proteína; FDAcp = fibra em detergente ácido corrigida para cinzas e proteína.

Para a determinação dos consumos de matéria seca (MS) e nutrientes, a quantidade de ração oferecida diariamente foi registrada, pesando-se também as sobras de cada animal, do $10^{\circ}$ ao $14^{\circ}$ dia. Foram colhidas amostras da dieta oferecida e das sobras, as quais foram encaminhadas ao LANA da Embrapa Semiárido para a realização das análises laboratoriais. Os consumos em 
g/animal/dia, porcentagem do peso corporal (PC) e $\mathrm{g} / \mathrm{kg}$ de peso metabólico $\left(\mathrm{kg}^{0,75}\right)$ de $\mathrm{MS}$ e dos nutrientes foram calculados por meio das seguintes equações: consumo (C) (g/animal/dia) = quantidade de MS, FDN, PB, EE, CHOT e CNF oferecida - quantidade de MS, FDN, PB, $\mathrm{EE}, \mathrm{CHOT}$ e $\mathrm{CNF}$ nas sobras; $\mathrm{C}(\%$ do $\mathrm{PC})=$ quantidade de MS, FDN, PB, EE, CHOT e CNF $(\mathrm{kg})$ consumidos * 100)/PC $(\mathrm{kg}) ; \mathrm{C}\left(\mathrm{g} / \mathrm{kg}^{0,75}\right)=$ quantidade de MS, FDN, PB, EE, CHOT e CNF $(\mathrm{kg})$ consumidos $* 100) / \mathrm{PC}^{0,75}$, sendo que os consumos de nutrientes foram calculados com base na MS.

A digestibilidade in vivo foi determinada pelo método de coleta total de fezes. Para isso, utilizaram-se bolsas e arreios de napa, que foram acoplados aos ovinos. A coleta das fezes foi realizada às $8: 00 \mathrm{~h}$ e 14:00h. Posteriormente, todo o conteúdo obtido foi pesado, homogeneizado e amostrado, retirando-se aproximadamente $10 \%$ da quantidade diária produzida. As amostras de fezes foram encaminhadas para as análises laboratoriais no LANA da Embrapa Semiárido. Antes do início do ensaio experimental, os animais foram mantidos por quatro dias com as bolsas para a coleta de fezes, para a adaptação.

As digestibilidades aparentes (DA) da MS, FDN, $\mathrm{PB}$, EE, CHOT e CNF expressas em porcentagem, foram calculadas por meio de equação proposta por Silva e Leão (1979): DA = [(MS ou nutrientes ingeridos (g) - MS ou nutrientes nas fezes (g)/(MS ou nutrientes ingeridos $(\mathrm{g})] * 100$.

Para a quantificação da produção de urina, foram utilizados baldes plásticos, devidamente higienizados, com a adição de $100 \mathrm{~mL}$ da solução de $\mathrm{HCl} 2 \mathrm{~N}$. Os baldes foram posicionados abaixo das gaiolas, durante os quatro últimos dias do experimento. Essas coletas foram realizadas às 10:00h, sendo a amostra de urina filtrada em peneira de malha fina forrada com gaze e quantificada numa proveta graduada em $\mathrm{mL}$. As amostras de urina coletadas (cerca de $10 \%$ da produção diária) foram acondicionadas em frascos plásticos providos de tampa e congeladas a $-10^{\circ} \mathrm{C}$. Ao final do ensaio experimental, as amostras foram descongeladas, compostas por animal e encaminhadas para a determinação dos teores de N, seguindo a metodologia descrita por Silva e Queiroz (2002).
$\mathrm{O}$ balanço de $\mathrm{N}$ (BN) foi obtido pela diferença entre o total de $\mathrm{N}$ ingerido (N-total) e o total de $\mathrm{N}$ excretado nas fezes (N-fezes) e na urina $(\mathrm{N}-$ urina). $\mathrm{O} \mathrm{N}$-ingerido foi estimado por meio da equação: $\mathrm{N}$-ingerido $=(\mathrm{N}$-ofertado $-\mathrm{N}$-das sobras). O N-excretado (fezes e urina) foi determinado por meio de análises laboratoriais.

O consumo de água também foi determinado por meio de pesagem da quantidade oferecida e das sobras, durante quatro dias. A água foi fornecida em baldes plásticos. Foram utilizados cinco baldes, semelhantes aos que foram usados para o fornecimento de água aos animais, para estimar a evaporação. A estimativa da ingestão de água foi calculada por meio da equação: $\mathrm{CA}=(\mathrm{AO}-\mathrm{SA})$ - Evp, em que $\mathrm{CA}=$ consumo de água; $\mathrm{AO}=$ água ofertada; $\mathrm{AS}=$ sobra de água; e Evp = evaporação.

O consumo de água oriundo da alimentação foi estimado por meio da determinação do teor de matéria seca (MS) dos alimentos e das sobras, utilizando-se a equação: consumo de água do alimento = umidade contida no ofertado $(\mathrm{Kg})-$ umidade contida nas sobras $(\mathrm{Kg})$. Para estimar o consumo total de água (CTA), foram somados os valores de ingestão de água (bebedouro) e a água proveniente da alimentação.

Os valores de água excretada nas fezes e na urina foram calculados mediante análise de MS (Silva e Queiroz, 2002), estimadas pela equação: água excretada nas fezes $=(1-$ MS das fezes $)$; e água excretada na urina $=(1-$ MS da urina $)$. Já a água total excretada foi estimada por meio da soma do volume de água excretada nas fezes e urina. O balanço hídrico foi estimado pela subtração do total de água excretada em relação ao total de água consumida, em kg/animal/dia.

O delineamento experimental foi o inteiramente ao acaso com silagens de três cultivares de capim-búfel e sete repetições. Todas as variáveis analisadas foram submetidas à análise de variância seguida pelo teste de Tukey. Foi utilizado o "PROC GLM - General Linear Models", do software Statistical Analysis System - SAS (Statistical..., 2002), considerando como significativos valores de probabilidade inferiores a $5 \%(\mathrm{P}<0,05)$. 


\section{RESULTADOS E DISCUSSÃO}

Os consumos de MS (g/dia, \% do PC e $\mathrm{PC}^{0,75}$ ) e o consumo de FDN (g/dia) não foram afetados $(\mathrm{P}>0,75)$ pelos cultivares de capim-búfel (Tab. 2).

O consumo de MS obtido na presente pesquisa, cujo valor médio foi de 919,2 g/animal/dia, é adequado para ovinos confinados nessa faixa de peso corporal e está dentro da faixa relatada na literatura. Bernardino et al. (2009) reportaram valor de consumo de MS médio de 903,8 g/animal/dia para ovinos confinados recebendo silagens de capim-elefante colhido aos 60 dias, o qual era bastante próximo ao encontrado no presente estudo.

Quanto ao consumo de MS, em relação ao peso corporal, o valor médio encontrado foi $2,87 \%$. Esse valor é superior aos relatados por Rêgo et al. (2010) e Teles et al. (2010). Em ambos os estudos cordeiros confinados foram alimentados com silagens de capim-elefante, e os consumos de MS (\% do PC) foram de 2,52\% e 2,07\%, respectivamente.

Tabela 2. Consumo por ovinos de matéria seca, de fibra em detergente neutro e de proteína bruta de silagens de três cultivares de capim-búfel

\begin{tabular}{|c|c|c|c|c|c|}
\hline \multirow{2}{*}{ Variável } & \multicolumn{3}{|c|}{ Cultivares } & \multirow{2}{*}{$\mathrm{CV}$} & \multirow{2}{*}{$\mathrm{P}$} \\
\hline & Tanzânia & Buchuma & Biloela & & \\
\hline Matéria seca (g/dia) & $838,8 \mathrm{a}$ & $1032,8 \mathrm{a}$ & $886,1 \mathrm{a}$ & 18,2 & 0,4822 \\
\hline Matéria seca (\% do PC) & $2,6 a$ & $3,3 \mathrm{a}$ & $2,7 \mathrm{a}$ & 19,7 & 0,7531 \\
\hline Matéria seca $\left(\mathrm{g} / \mathrm{kg} \mathrm{PC}{ }^{0,75}\right)$ & $62,7 \mathrm{a}$ & $77,7 \mathrm{a}$ & $65,2 \mathrm{a}$ & 16,3 & 0,8581 \\
\hline FDN (g/dia) & $581,0 \mathrm{a}$ & $677,4 \mathrm{a}$ & $537,6 a$ & 18,2 & 0,1392 \\
\hline FDN (\% do PC) & $1,8 \mathrm{ab}$ & $2,2 \mathrm{a}$ & $1,7 \mathrm{~b}$ & 16,8 & 0,0263 \\
\hline FDN (g/Kg PC $\left.{ }^{0,75}\right)$ & $43,4 \mathrm{ab}$ & $51,0 \mathrm{a}$ & $39,5 b$ & 15,8 & 0,0215 \\
\hline Proteína bruta (g/dia) & $77,7 \mathrm{a}$ & $59,3 \mathrm{~b}$ & $78,9 a$ & 21,1 & 0,0127 \\
\hline Proteína bruta (\% do PC) & $0,24 \mathrm{a}$ & $0,19 b$ & $0,24 \mathrm{a}$ & 17,9 & 0,0258 \\
\hline Proteína bruta $\left(\mathrm{g} / \mathrm{Kg} \mathrm{PC}{ }^{0,75}\right)$ & $5,80 \mathrm{a}$ & $4,45 b$ & $5,80 \mathrm{a}$ & 17,1 & 0,0177 \\
\hline
\end{tabular}

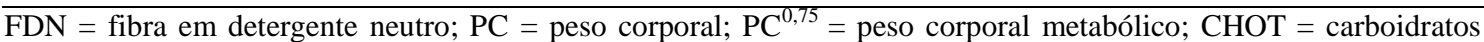
totais; $\mathrm{CNF}=$ carboidratos não fibrosos; $\mathrm{CV}=$ coeficiente de variação $(\%) ; \mathrm{P}=$ probabilidade.

Em relação ao peso metabólico, os consumos de MS encontrados no presente estudo, com valor médio de 68,5 $\mathrm{g} / \mathrm{PC}^{0,75}$, foram superiores aos observados por Ferreira et al. (2009), da ordem de $34,65 \mathrm{~g} / \mathrm{PC}^{0,75}$, quando trabalharam com ovinos confinados alimentados com silagens de capim-elefante. De um modo geral, os valores de consumo de MS (g/dia, \% do PC e $\mathrm{PC}^{0,75}$ ), observados na presente pesquisa, indicam o bom potencial dos cultivares de capim-búfel para a alimentação de ovinos, sem prejuízos ao consumo desses animais.

Foi observado consumo médio de FDN de 598,7 g/animal/dia, sendo este semelhante a estudos com outros capins tropicais reportados na literatura. Bernardino et al. (2009) observaram consumo de 692,7g/animal/dia em ovinos recebendo silagem de capim-elefante, semelhante ao observado na presente pesquisa.

Alimentados com capim-búfel do cultivar Buchuma, os ovinos consumiram mais FDN $(\mathrm{P}<0,05)$ em relação aos que receberam $\mathrm{O}$ cultivar Biloela, em porcentagem do $\mathrm{PC}$ e em $\mathrm{g} / \mathrm{Kg} \mathrm{PC}^{0,75}$, o que pode ser justificado pelos teores de FDN desses cultivares, já que o Buchuma apresentou $77,38 \%$ de FDN e o Biloela, 73,41\%. Além disso, o consumo de MS do cultivar Buchuma foi 1032,8g/animal/dia, enquanto que para a Biloela foi $886,1 \mathrm{~g} /$ animal/dia, contribuindo para os maiores consumos de FDN (\% do PC e em g/kg PC ${ }^{0,75}$ ), para os animais alimentados com o cultivar Buchuma. 
Por outro lado, o cultivar Buchuma proporcionou menores $(\mathrm{P}<0,05)$ consumos de $\mathrm{PB}(\mathrm{g} / \mathrm{dia}, \%$ do $\mathrm{PC}$ e $\mathrm{g} / \mathrm{kg} \quad \mathrm{PC}^{0,75}$ ) em relação ao Tanzânia e Biloela, pelo fato de a silagem desse cultivar apresentar menor teor de $\mathrm{PB}$ em relação às outras. No entanto, até mesmo para o cultivar Buchuma, que promoveu menores consumos de PB na presente pesquisa, os valores encontrados são superiores aos relatados por Teles et al. (2010). Estes trabalharam com ovinos alimentados com silagens de capim-elefante e encontraram consumos de $\mathrm{PB}$ de $0,13 \%$ de $\mathrm{PC}$ e $2,76 \% \mathrm{~g} / \mathrm{kg}$ de $\mathrm{PC}^{0,75}$, sugerindo que os cultivares de capim-búfel não prejudicam o consumo de nutrientes (PB e FDN) dos animais.

Foi observado maior $(\mathrm{P}<0,05)$ consumo de extrato etéreo (EE) em g/dia, porcentagem do PC e $\mathrm{g} / \mathrm{kg}$ de $\mathrm{PC}^{0,75}$ dos animais que receberam silagem do cultivar Buchuma em relação aos cultivares Tanzânia e Biloela. Isso pode ser explicado pelo maior teor de EE contido na silagem desse cultivar, associado ao consumo de MS semelhante entre os ovinos alimentados com os três cultivares de capim-búfel no presente estudo (Tab. 3).

Em estudos conduzidos por Rêgo et al. (2010), com silagem de capim-elefante colhido aos 70 dias, foram observados consumos de $\mathrm{EE}$ de $0,09 \%$ do peso corporal e $1,75 \mathrm{~g} /$ peso metabólico, semelhantes aos valores observados no presente estudo, cuja média foi de $0,05 \%$ de PC e $1,19 \mathrm{~g} / \mathrm{kg}$ de peso metabólico.

Não houve influência $(\mathrm{P}>0,05)$ dos cultivares de capim-búfel sobre os consumos de CHOT em g/dia e porcentagem de PC, apresentando consumo médio de 647,2 e 2,0, respectivamente (Tab. 3). Em silagem de capim-elefante colhido aos 70 dias, Rêgo et al. (2010) e Teles et al. (2010) reportaram consumos de CHOT da ordem de 1,91 e 1,59 \% do PC, colaborando com os valores observados no presente estudo.

Em g/kg de peso metabólico, os ovinos alimentados com silagem do cultivar Buchuma tiveram maior consumo em relação à Tanzânia e à Biloela (Tab. 3). Estudos de Rêgo et al. (2010) e Teles et al. (2010) reportam valores de consumos de 38,76 e $33,76 \mathrm{~g} / \mathrm{kg}$ de peso metabólico de CHOT, respectivamente, sendo semelhantes, porém inferiores aos valores observados no presente estudo, que apresentou um consumo médio de $48,23 \mathrm{~g} / \mathrm{kg}$ de peso metabólico.

Tabela 3. Consumo, por ovinos, de extrato etéreo, carboidratos totais, carboidratos não fibrosos e nutrientes digestíveis totais de silagens de três cultivares de capim-búfel

\begin{tabular}{|c|c|c|c|c|c|}
\hline \multirow{2}{*}{ Variável } & \multicolumn{3}{|c|}{ Cultivares } & \multirow{2}{*}{$\mathrm{CV}$} & \multirow{2}{*}{$\mathrm{P}$} \\
\hline & Tanzânia & Buchuma & Biloela & & \\
\hline Extrato etéreo (g/dia) & $12,04 \mathrm{~b}$ & $21,68 \mathrm{a}$ & $14,15 b$ & 17,4 & 0,0001 \\
\hline Extrato etéreo (\% do PC) & $0,038 b$ & $0,069 \mathrm{a}$ & $0,044 b$ & 19,0 & 0,0001 \\
\hline Extrato etéreo $\left(\mathrm{g} / \mathrm{kg} \mathrm{PC}{ }^{0,75}\right)$ & $0,90 \mathrm{~b}$ & $1,63 \mathrm{a}$ & $1,05 b$ & 18,1 & 0,0010 \\
\hline CHOT (g/dia) & $592,66 a$ & $744,49 a$ & $604,52 \mathrm{a}$ & 17,2 & 0,3640 \\
\hline CHOT (\% do PC) & $1,87 \mathrm{a}$ & $2,37 \mathrm{a}$ & $1,86 \mathrm{a}$ & 18,4 & 0,3101 \\
\hline CHOT (g/kg PC $\left.{ }^{0,75}\right)$ & $44,26 b$ & $56,02 \mathrm{a}$ & $44,40 \mathrm{~b}$ & 17,5 & 0,0268 \\
\hline CNF (g/dia) & $75,44 b$ & $152,97 \mathrm{a}$ & $123,51 \mathrm{a}$ & 18,6 & 0,0001 \\
\hline CNF (\% do PC) & $0,24 \mathrm{c}$ & $0,49 \mathrm{a}$ & $0,38 b$ & 19,7 & 0,0001 \\
\hline $\mathrm{CNF}\left(\mathrm{g} / \mathrm{kg} \mathrm{PC}{ }^{0,75}\right)$ & $5,64 \mathrm{c}$ & $11,50 \mathrm{a}$ & $9,08 \mathrm{~b}$ & 19,0 & 0,0001 \\
\hline
\end{tabular}

FDN = fibra em detergente neutro; $\mathrm{PC}=$ peso corporal; $\mathrm{PC}^{0,75}=$ peso corporal metabólico; $\mathrm{CHOT}=$ carboidratos totais; $\mathrm{CNF}=$ carboidratos não fibrosos; $\mathrm{CV}=$ coeficiente de variação $(\%) ; \mathrm{P}=$ probabilidade.

Maiores consumos $(\mathrm{P}<0,05)$ de $\mathrm{CNF}$ em g/dia foram observados nos ovinos alimentados com os cultivares Buchuma e Biloela, cujo consumo médio foi de $138,2 \mathrm{~g} /$ dia, correspondendo a uma diferença de $29,4 \%$ em relação ao cultivar Tanzânia (Tab. 3).
Ovinos alimentados com silagem de Buchuma apresentaram maiores $(\mathrm{P}<0,05)$ consumos de $\mathrm{CNF}$ em porcentagem do $\mathrm{PC}$ e $\mathrm{g} / \mathrm{kg}$ de $\mathrm{PC}^{0,75}$, seguidos dos que receberam cultivares Biloela $\mathrm{e}$ Tanzânia. Rêgo et al. (2010) e Teles et al. (2010) reportaram em silagens de capim-elefante colhido aos 70 dias, consumos de CNF de 0,08 e $0,07 \%$ do PC e 1,61 e $1,51 \mathrm{~g} / \mathrm{kg}$ de 
$\mathrm{PC}^{0,75}$, respectivamente, valores inferiores aos observados no presente estudo para os animais que consumiram a cultivar Buchuma.

Os coeficientes de digestibilidade (Tab. 4) da MS e MO não foram influenciados $(\mathrm{P}>0,05)$ pelos cultivares de capim-búfel. Os valores médios foram $54,1 \%$ e $53,1 \%$, respectivamente. Esses valores obtidos são considerados baixos, em relação a outras forragens, como relatado por Ítavo et al. (2009) para silagens de milho e sorgo com valores de digestibilidade da MS de 74,3\% e $75,3 \%$, respectivamente. Porém, quando comparados com outras silagens de capins tropicais, os valores obtidos estão dentro da faixa normal. Rêgo et al. (2010) avaliaram o coeficiente de digestibilidade de silagens de capim-elefante e observaram coeficientes de digestibidade da MS e MO $(51,14 \%$ e $52,68 \%$, respectivamente) semelhantes aos observados no presente estudo.

Foi observado maior coeficiente de digestibilidade da proteína $(\mathrm{P}<0,05)$ para $\mathrm{O}$ cultivar Tanzânia, seguido do Biloela e Buchuma. Provavelmente, esse resultado ocorreu pelos maiores consumos de PB proporcionados pelos cultivares Tanzânia e Biloela em relação à Buchuma. Ferreira et al. (2009) também atribuíram maiores coeficientes de digestibilidade da proteína de silagens de capimelefante em função de maiores consumos de proteína pelos animais.

Tabela 4. Coeficiente de digestibilidade aparente da matéria seca e nutrientes de silagens de três cultivares de capim-búfel consumidas por ovinos

\begin{tabular}{|c|c|c|c|c|c|}
\hline \multirow[t]{2}{*}{ Variável } & \multicolumn{3}{|c|}{ Cultivares } & \multirow{2}{*}{$\mathrm{CV}$} & \multirow{2}{*}{$\mathrm{P}$} \\
\hline & Tanzânia & Buchuma & Biloela & & \\
\hline Matéria seca & $53,0 \mathrm{a}$ & $56,5 \mathrm{a}$ & $52,7 \mathrm{a}$ & 7,0 & 0,1000 \\
\hline Matéria orgânica1 & $53,4 \mathrm{a}$ & $53,9 \mathrm{a}$ & $52,1 \mathrm{a}$ & 6,9 & 0,5098 \\
\hline Proteína bruta $^{1}$ & $60,0 \mathrm{a}$ & $37,3 \mathrm{c}$ & $50,4 b$ & 10,4 & 0,0001 \\
\hline $\mathrm{FDN}^{1}$ & $47,5 \mathrm{a}$ & $47,2 \mathrm{a}$ & $41,4 b$ & 8,7 & 0,0166 \\
\hline Extrato etéreo ${ }^{1}$ & $32,8 \mathrm{a}$ & $41,4 \mathrm{a}$ & $32,4 a$ & 30,0 & 0,9502 \\
\hline Carboidratos totais $^{1}$ & $47,5 \mathrm{a}$ & $53,2 \mathrm{a}$ & $50,3 \mathrm{a}$ & 10,0 & 0,3093 \\
\hline $\mathrm{CNF}^{1}$ & $88,1 \mathrm{~b}$ & $95,9 a$ & $95,8 \mathrm{a}$ & 4,6 & 0,0033 \\
\hline
\end{tabular}

MS = matéria seca; FDN $=$ fibra em detergente neutro; $\mathrm{CNF}=$ carboidratos não fibrosos; NDT $=$ nutrientes digestíveis totais; $\mathrm{CV}=$ coeficiente de variação $(\%) ; \mathrm{P}=$ probabilidade; ${ }^{1}(\%$ da matéria seca $)$.

Entre os cultivares Tanzânia e Biloela, a diferença dos coeficientes de digestibidade da PB pode ser atribuída aos maiores teores de $\mathrm{PB}$ presentes no cultivar Tanzânia, associados a menores teores de lignina, NIDN e NIDA em relação ao Biloela. A maior presença de lignina, NIDN e NIDA no cultivar Biloela pode ter prejudicado a digestibilidade aparente da proteína. Ferreira et al. (2009) reportaram valores de coeficiente de digestibilidade da $\mathrm{PB}$ de $37,7 \%$ em silagens de capim-elefante, enquanto Teles et al. (2010) observaram média de $46,90 \%$, semelhantes aos observados no presente estudo.

A digestibilidade aparente da FDN (Tab. 4) não diferiu $(\mathrm{P}>0,05)$ entre os cultivares Tanzânia e Buchuma. Entretanto, menor valor de digestibilidade aparente da FDN $(\mathrm{P}<0,05)$ foi observado para o cultivar Biloela, o que também pode ser atribuído aos maiores valores de NIDN,
NIDA e lignina em relação aos outros dois cultivares avaliados.

Os coeficientes de digestibilidade da FDN observados no presente estudo estão condizentes com os valores relatados na literatura para outras silagens de capins tropicais. Neiva et al. (2006), Bernardino et al. (2009) e Rêgo et al. (2010) reportam valores de $47,8 \%, 61,1 \%$ e $51,1 \%$, respectivamente, para silagens de capim-elefante colhidas aos 80,60 e 70 dias, respectivamente.

Não se observou diferença $(\mathrm{P}>0,05)$ para os coeficientes de digestibilidade do EE e CHOT nas silagens de cultivares de capim-búfel consumidas pelos ovinos, apresentando um coeficiente médio de $35,5 \%$ e $50,4 \%$, respectivamente. Isso pode ser explicado pelos semelhantes consumos de EE e CHOT. No presente estudo, foi observado um coeficiente de digestibilidade do EE inferior ao valor de $61,1 \%$ reportado por Teles et al. (2010), que 
trabalharam com silagem de capim-elefante colhido aos 70 dias. Já para o coeficiente de digestibilidade dos CHOT, esses mesmos autores observaram um valor de $62,6 \%$, semelhante ao relatado no presente estudo.

Foi observado maior coeficiente de digestibilidade dos CNF $(\mathrm{P}<0,05)$ para os cultivares Buchuma e Biloela em relação ao Tanzânia. Provavelmente esse resultado ocorreu pelos maiores consumos dos CNF proporcionados pelos cultivares Buchuma e Biloela em relação ao Tanzânia. Teles et al. (2010) reportaram valores de $89,25 \%$ de digestibilidade aparente dos CNF nas silagens de capim-elefante colhido aos 70 dias de idade, similar aos valores observados no presente estudo, com um coeficiente de digestibilidade dos CNF médio de 93,27\%.
Houve maior ingestão de $\mathrm{N}(\mathrm{P}<0,05)$ pelos animais alimentados com os cultivares Tanzânia e Biloela em relação ao Buchuma (Tab. 5), o que ocorreu em consequência dos menores teores, consumo e digestibilidade aparente da PB do cultivar Buchuma em relação aos demais. Mizubuti et al. (2007) reportaram ingestão de N variando de $10,29 \mathrm{~g} /$ dia a $13,15 \mathrm{~g} / \mathrm{dia}$, semelhante aos valores observados no presente estudo, que mostraram ingestão média de 11,5g/dia.

Os animais alimentados com o cultivar Biloela apresentaram maior teor de $\mathrm{N}$ nas fezes (g/dia), em relação aos alimentados com o cultivar Tanzânia, em razão dos maiores coeficientes de digestibilidade aparente do cultivar Tanzânia em comparação com o Biloela.

Tabela 5. Balanço de nitrogênio de ovinos alimentados com silagens de três cultivares de capim-búfel

\begin{tabular}{lccccc}
\hline \multirow{2}{*}{\multicolumn{1}{c}{ Variável }} & \multicolumn{3}{c}{ Cultivares } & CV & P \\
\cline { 2 - 5 } & Tanzânia & Buchuma & Biloela & & \\
\hline N ingerido, g/dia & $12,4 \mathrm{a}$ & $9,5 \mathrm{~b}$ & $12,6 \mathrm{a}$ & 17,0 & 0,0130 \\
$\mathrm{~N}$ fecal, g/dia & $5,0 \mathrm{~b}$ & $5,8 \mathrm{ab}$ & $6,2 \mathrm{a}$ & 15,9 & 0,0001 \\
$\mathrm{~N}$ fecal, \% N ingerido & $40,0 \mathrm{c}$ & $61,7 \mathrm{a}$ & $49,8 \mathrm{~b}$ & 9,6 & 0,0001 \\
$\mathrm{~N}$ na urina, g/dia & $2,4 \mathrm{a}$ & $2,4 \mathrm{a}$ & $2,5 \mathrm{a}$ & 30,1 & 0,7185 \\
$\mathrm{~N}$ na urina, \% N ingerido & $19,4 \mathrm{a}$ & $25,0 \mathrm{a}$ & $20,7 \mathrm{a}$ & 28,9 & 0,4545 \\
N absorvido, g/dia & $7,5 \mathrm{a}$ & $3,7 \mathrm{~b}$ & $6,4 \mathrm{a}$ & 22,2 & 0,0001 \\
Balanço de N, g/dia & $5,1 \mathrm{a}$ & $1,3 \mathrm{~b}$ & $3,9 \mathrm{a}$ & 36,6 & 0,0001 \\
\hline
\end{tabular}

$\mathrm{N}=$ nitrogênio; $\mathrm{CV}=$ coeficiente de variação; $\mathrm{P}=$ probabilidade.

$\mathrm{Na}$ porcentagem do $\mathrm{N}$ ingerido, os animais alimentados com o cultivar Buchuma apresentaram maiores teores $(\mathrm{P}<0,05)$ de $\mathrm{N}$ nas fezes em relação aos demais, seguidos pelos que receberam Biloela e Tanzânia. Isso pode ser justificado pelos menores coeficientes de digestibilidade do Buchuma em relação a Tanzânia e Biloela. O N na urina (g/dia e \% do N ingerido) não foi influenciado pelos cultivares de capim-búfel ( $\mathrm{P}>0,05)$ (Tab. 5). Aparentemente, o $\mathrm{N}$ em excesso, oriundo de um maior consumo ou menor digestibilidade aparente da PB, foi eliminado principalmente via fezes.

O $\mathrm{N}$ absorvido foi maior $(\mathrm{P}<0,05)$ para os animais alimentados com os cultivares Tanzânia e Biloela em relação ao Buchuma, em virtude das maiores ingestões e melhores coeficientes de digestibilidade da PB dos cultivares Tanzânia e Biloela (Tab. 5).

$\mathrm{O} \mathrm{BN}$ foi positivo para os animais alimentados com as silagens de todos os cultivares capimbúfel avaliados (Tab. 5), indicando que o animal não necessitou deslocar reservas proteicas corporais para suprir suas exigências nutricionais. Os $\mathrm{BN}$ foram considerados adequados quando comparados a outros estudos que utilizaram silagens de capins tropicais na alimentação de ovinos. Nos estudos de Ferreira et al. (2009) e Teles et al. (2010), foram relatados $\mathrm{BN}$ negativos $(-0,61$ e $-0,11)$ quando ovinos foram alimentados com silagens de capim-elefante.

Houve menor $\mathrm{BN}(\mathrm{P}<0,05)$ para os animais alimentados com o cultivar Buchuma em relação 
aos demais, em função dos menores valores de $\mathrm{N}$ ingerido e dos menores coeficientes de digestibilidade, em consequência de uma menor oferta de $\mathrm{N}$ alimento. Isso corroborou os resultados relatados por Mizubuti et al. (2007) e Santos et al. (2010) que observaram maiores valores de $\mathrm{BN}$ para os animais que receberam dietas com maiores concentrações de $\mathrm{N}$, contribuindo para incrementar o consumo de N.

Foi observado um maior consumo de água a partir da alimentação $(\mathrm{P}<0,05)$ para os animais alimentados com silagens do cultivar Biloela, seguidos pelos que receberam Buchuma $\mathrm{e}$ Tanzânia (Tab. 6), sendo justificado pelos maiores valores de MS para a Tanzânia, seguido da Buchuma e Biloela, no material ensilado.

A quantidade de água ingerida diretamente no bebedouro e excretada nas fezes não foi influenciada $(\mathrm{P}>0,05)$ pelos cultivares de capimbúfel. No caso da água ingerida diretamente do bebedouro, isso provavelmente ocorreu em virtude dos semelhantes consumos de MS e, em consequência, de água, para os animais alimentados com os três cultivares de capimbúfel. $\mathrm{O}$ consumo de água diretamente do bebedouro foi em média $0,95 \mathrm{~kg} / \mathrm{animal} / \mathrm{dia}$, correspondendo a aproximadamente $43,7 \%$ do consumo total de água.

Os valores de CTA no presente estudo, com média de $2,29 \mathrm{~kg} /$ dia, são próximos aos relatados por Angaga et al. (1992), que determinaram o balanço hídrico de ovinos da raça Yankasa e relataram valores de 2,22kg/dia de CTA.

O uso da equação proposta pelo National Research Council - NRC (National..., 2007) para determinar o consumo total de água pelo animal, em que o CTA $(\mathrm{kg} / \mathrm{dia})=\mathrm{CMS}$ x 3,86 - 0,99, proporciona valores semelhantes aos observados no presente estudo. Utilizando na equação o valor médio de consumo de MS observado nesta pesquisa $(0,92 \mathrm{~kg} / \mathrm{animal} / \mathrm{dia})$, o valor de CTA obtido é de $2,56 \mathrm{~kg} / \mathrm{animal} / \mathrm{dia}$.

Tabela 6. Valores médios diários do consumo e excreção de água, do balanço hídrico e água da dieta em relação à água total, de ovinos alimentados com silagens de três cultivares de capim-búfel

\begin{tabular}{lccccc}
\hline \multirow{2}{*}{ Variável, kg/dia } & \multicolumn{3}{c}{ Cultivares } & \multirow{2}{*}{ CV } & P \\
\cline { 2 - 4 } & Tanzânia & Buchuma & Biloela & & 0,0001 \\
CAD & $1,08 \mathrm{c}$ & $1,31 \mathrm{~b}$ & $1,61 \mathrm{a}$ & 5,76 & 0,1749 \\
CAO & $0,76 \mathrm{a}$ & $1,14 \mathrm{a}$ & $0,95 \mathrm{a}$ & 25,43 & 0,0001 \\
CTA & $1,85 \mathrm{~b}$ & $2,45 \mathrm{a}$ & $2,56 \mathrm{a}$ & 10,47 & $0,000,259$ \\
CAD, \% do CTA & $61,75 \mathrm{a}$ & $57,84 \mathrm{a}$ & $65,03 \mathrm{a}$ & 9,25 & 0,2949 \\
AEF & $0,36 \mathrm{a}$ & $0,45 \mathrm{a}$ & $0,41 \mathrm{a}$ & 12,15 & 0,1098 \\
AEU & $0,44 \mathrm{~b}$ & $0,61 \mathrm{a}$ & $0,73 \mathrm{a}$ & 19,19 & 0,0001 \\
ATE & $0,80 \mathrm{~b}$ & $1,07 \mathrm{a}$ & $1,13 \mathrm{a}$ & 12,58 & 0,0001 \\
BH & $1,05 \mathrm{~b}$ & $1,38 \mathrm{a}$ & $1,42 \mathrm{a}$ & 14,36 & 0,0011 \\
\hline
\end{tabular}

$\mathrm{CAD}=$ consumo de água da dieta; $\mathrm{CAO}=$ consumo de água ofertada; $\mathrm{CTA}=$ consumo total de água; $\mathrm{AEF}=$ água excretada nas fezes; $\mathrm{AEU}$ = água excretada na urina; $\mathrm{ATE}=$ água total excretada; $\mathrm{BH}=$ balanço hídrico; $\mathrm{CV}=$ coeficiente de variação $(\%)$

O consumo de água (\% do CTA) oriunda da dieta não foi afetado pelos cultivares de capim-búfel $(\mathrm{P}>0,05)$. Em média, $56,3 \%$ do total de água ingerida foram provenientes da dieta, demonstrando a importância da conservação das forragens na forma de silagem, visando ao aumento no suprimento hídrico para os animais criados nas regiões com maiores deficiências hídricas do semiárido brasileiro, além da provisão de forragem, na forma de silagem, para a alimentação dos mesmos.

Foram observadas menores quantidades de água excretada $(\mathrm{kg} / \mathrm{dia})(\mathrm{P}<0,05)$ pela urina e total (urina + fezes) para os animais alimentados com o cultivar Tanzânia em relação àqueles alimentados com os outros cultivares, em decorrência das menores ingestões de água dos animais alimentados com silagens do cultivar Tanzânia. Em geral, as excreções de água pelos ovinos alimentados com as silagens de capimbúfel variaram de $43,2 \%$ a $44,1 \%$ do CTA.

Os balanços hídricos (ou água retida) dos animais alimentados com as silagens de capimbúfel foram positivos, independentemente dos cultivares (Tab. 6). O balanço hídrico foi menor para os animais que receberam silagens do 
cultivar Tanzânia em comparação com aqueles alimentados com Biloela e Buchuma, devido às menores ingestões de água proporcionadas pelo cultivar Tanzânia, em função dos maiores teores de MS. A menor excreção de água pela urina apresentada pelos animais alimentados com o cultivar Tanzânia não foi suficiente para deixar os balanços hídricos semelhantes entre os três cultivares avaliados.

É relevante destacar que o $\mathrm{BH}$ do presente estudo não considera as perdas inerentes à transpiração que, segundo Angaga et al. (1992), representa cerca de $70 \%$ das perdas totais.

O consumo e a digestibilidade aparente da MS e nutrientes, além dos balanços de $\mathrm{N}$ e água dos ovinos alimentados com as silagens de capimbúfel, foram considerados adequados, sendo indicativos relevantes do potencial dessa planta como recurso forrageiro para a alimentação de ovinos e da importância da conservação da mesma na forma de silagem, visando melhorar o suporte hídrico para os animais criados no semiárido brasileiro.

\section{CONCLUSÃO}

As silagens de capim-búfel dos cultivares Tanzânia, Buchuma e Biloela são consumidas adequadamente, com bons coeficientes de digestibilidade da matéria seca e nutrientes, com exceção da silagem do cultivar Buchuma, que apresenta baixo coeficiente de digestibilidade para a PB. Os balanços de nitrogênio e hídrico são positivos, com aproximadamente $60 \%$ do consumo total de água dos ovinos sendo oriundos da alimentação.

\section{REFERÊNCIAS}

ANGAGA, A.A. Water utilization by sheep and goats in northern Nigeria. Rev. Mund. Zootec., v.73, p. 9-14, 1992.

ARAÚJO, G.G.L.; VOLTOLINI, T.V.; CHIZZOTTI, M.L. et al. Water and small ruminant production. Rev. Bras. Zootec., v.39, p.326-336, 2010 (supl. especial)

BERCHIELLI, T.T.; PIRES, A.V.; OLIVEIRA, S.G. Nutrição de Ruminantes: Consumo de Forragens. Jaboticabal: Funep, 2006. 583p.
BERNARDINO, F.S.; GARCIA, R.; TONUCCI, R.G. et al. Consumo e digestibilidade de nutrientes de silagens de capim-elefante com casca de café, por ovinos. Rev. Bras. Saúde Prod. Anim., v.10, p.460-469, 2009.

FERREIRA, A.C.H.; NEIVA, J.N.M.; RODRIGUEZ, N.M. et al. Avaliação nutricional do subproduto da agroindústria de abacaxi como aditivo de silagem de capim-elefante. Rev. Bras. Zootec., v.38, p.223-229, 2009.

GIULIETTI, A.M.; DU BOCANEGRA NETA, A.L.; CASTRO, A.A.J.F. et al. Diagnóstico da vegetação nativa do bioma da caatinga In: Biodiversidade da Caatinga: áreas e ações prioritárias para a conservação. Brasilia: MMAUFPE, Brasília, DF, 2004. p.47-90.

ÍTAVO, C.C.B.F; MORAIS, M.G; ÍTAVO, L.C.V. et al. Consumo e digestibilidade de nutrientes de dietas com silagens de grãos úmidos de milho ou sorgo, em ovinos. Arq. Bras. Med. Vet. Zootec., v.61, p.452-459, 2009.

MIZUBUTI, I.Y.; RIBEIRO, E.L.A.; ROCHA, M.A. et al. Consumo médio e digestibilidade do feno de capim "Coast cross" Cynodon dactylon (L.) pers.) e feijão guandu (Cajanus cajan (L.) Millsp) em carneiros submetidos a dois regimes alimentares. Semina: Cienc. Agrárias, v.28, p.513-520, 2007.

NATIONAL research council - NRC. Nutrient requirements of dairy cattle. 7. ed. Washington, D.C., 2001. 363p.

NATIONAL research council - NRC. Nutrient requirements of sheep. 6. ed. Washington: National Academy of Science, 2007. 99 p.

NEIVA, J.N.M.; NUNES, F.C.S.; CÂNDIDO, M.J.D. et al. Valor nutritivo de silagens de capim-elefante enriquecidas com subproduto do processamento do maracujá. Rev. Bras. Zootec., v.35, p.1845-1851, 2006.

OLIVEIRA, M.C. Capim buffel: Produção $e$ Manejo nas regiões secas do Nordeste. Petrolina: EMBRAPA/CPATSA, 1993. 18p. (Circular Técnica).

RÊGO, M.M.T.; NEIVA, J.N.M.; DO RÊGO, A.C. et al. Intake, nutrients digestibility and nitrogen balance of elephant grass silages with mango by-product addition. Rev. Bras. Zootec., v.39, p.74-80, 2010. 
SANTOS, S.A.; CAMPOS, J.M.S.; VALADARES FILHO, S.C. et al. Balanço de nitrogênio em fêmeas leiteiras em confinamento alimentadas com concentrado à base de farelo de soja ou farelo de algodão. Rev. Bras. Zootec., v.39, p.1135-1140, 2010.

SILVA, D.J.; QUEIROZ, A.C. Análise de alimentos: métodos químicos e biológicos. Viçosa, MG: Editora UFV, 2002. 235p.

SILVA, J.F.C., LEÃO, M.I. 1979. Fundamentos de nutrição dos ruminantes. Piracicaba: Livroceres. 380p.
SNIFFEN, C.J.; O'CONNOR, D.J.; Van SOEST, P.J. et al. A net carbohydrate and protein system for evaluating cattle diets: carbohydrate and protein availability. J. Anim. Sci., v.70, p.35623577, 1992.

STATISTICAL analysis system - SAS. SAS user's guide: Stat, Version 9.1, 4.1.ed. Cary, NC: SAS Institute, 2002, 466p.

TELES, M.M.; NEIVA, J.N.M.; CLEMENTINO, R.H. et al. Consumo, digestibilidade de nutrientes e balanço de nitrogênio da silagem de capim-elefante com adição de pedúnculo de caju desidratado. Cienc. Rural, v.40, p.427-433, 2010. 